Área Abierta. Revista de comunicación

audiovisual y publicitaria

ISSN: 2530-7592 / ISSNe: 1578-8293

https://dx.doi.org/10.5209/arab.77149

\title{
Sans Soleil, donde todo se comunica
}

\author{
Isleny Cruz-Carvajal ${ }^{1}$
}

Recibido: 2 de julio de 2021 / Aceptado: 18 de septiembre de 2021

Resumen. Sans Soleil - Chris Marker, 1983- representa el nacimiento oficial del ensayo cinematográfico por haber revelado al cine las propiedades canónicas de esta modalidad cada vez más fértil en el audiovisual contemporáneo. Coincidiendo con el centenario del nacimiento de su autor, el objetivo de este artículo es aportar un estudio específico de los mecanismos con los que Marker, heredero directo de Montaigne, traduce la forma-pensamiento en mecanismos estrictamente audiovisuales, simultáneos e incluso a veces independizados de los verbales atribuidos por principio al ensayo. Más allá del modo enunciativo en el que hasta ahora se han centrado la mayoría de estudios sobre Sans Soleil, este análisis toma como referencia la teoría literaria del macrogénero argumentativo, donde se funden ciencia y poesía. Las figuras retóricas producidas en el montaje se revelan como elemento primordial para reproducir, entre otras claves, el flujo de la memoria-conciencia y la interconexión entre las múltiples dimensiones de la Historia, el pensamiento y la emoción.

Palabras clave: Chris Marker; Sans Soleil; Ensayo Fílmico; Metacine; Retórica Fílmica; Noosfera

\section{[en] Sans Soleil, Where Everything Communicates}

\begin{abstract}
Sans Soleil - Chris Marker, 1983 - represents the official birth of the cinematographic essay for having revealed to cinema the canonical properties of this increasingly fertile modality in the contemporary audiovisual. Coinciding with the centenary of the birth of its author, the objective of this article is to provide a specific analysis of the mechanisms by which Marker, Montaigne's direct heir, translates thought-form into strictly audiovisual mechanisms, simultaneous and sometimes even independent of verbal mechanisms that are attributed by principle to the essay. Beyond the enunciative mode on which most of the studies on Sans Soleil have focused so far, this analysis takes as a reference the literary theory of the argumentative macrogenre, where science and poetry merge. The rhetorical figures produced in the montage are revealed as a primary element to reproduce, among other keys, the flow of memory-consciousness and the interconnection between the multiple dimensions of History, thought and emotion.
\end{abstract}

Keywords: Chris Marker; Sans Soleil; Film Essay; Metacinema; Film Rhetoric; Noosphere

Sumario. 1. Introducción. 2. Experiencias históricas en la imagen-memoria. 3. Macroestructura y fragmentación. 4. El estilo es el montaje. 5. El observador mirado. 6. Conclusiones.

Cómo citar. Cruz-Carvajal, Isleny (2021). Sans Soleil, donde todo se comunica. Área Abierta. Revista de comunicación audiovisual y publicitaria 21 (3), 387-403, https://dx.doi.org/10.5209/arab.77149

1 Universidad Rey Juan Carlos (España).

E-mail: isleny.cruz.carvajal@urjc.es

ORCID: https://orcid.org/0000-0001-5959-629X 


\section{Introducción}

Creada por un poeta fílmico que en el año 2021 cumpliría cien años, Sans Soleil - Chris Marker, 1983 - es un punto de inflexión en la historia universal del ensayo. Del ensayo en estado puro, como una forma que comunica la conjunción entre razón y emoción latente en la raíz de toda cultura humana (Machado, 2007; Cuesta, 2009). A esta obra le correspondió homologar a lenguaje fílmico los principios que desde el Renacimiento y con Michel de Montaigne se empezaron a instaurar en una manifestación literaria situada entre la ciencia y la poesía, con la experiencia subjetiva como forma pensante. A Max Bense (1942), Theodor Adorno (1962) y George Lukács (1975) les correspondería formular sus bases filosóficas para que, años después, la teoría literaria se encargara de sistematizarlas en el macrogénero argumentativo (Aullón de Haro, 1992; Gómez-Martínez, 1981), donde se combinan principios enunciativos y rasgos de lenguaje que esta gran tesis markeriana reúne integralmente (Corrigan, 2011), en una especie de continuación, pero en otro soporte, que hoy se presenta como una de las manifestaciones más fértiles de la cultura audiovisual (Mínguez, 2019: 11). A diferencia de Montaigne, cuyas innovaciones tardaron dos siglos en ser reconocidas como joyas (Deltell, 2019: 143), el cineasta francés se benefició de un contexto tecnológico, el de finales del siglo XX, que rápidamente hizo proliferar y difundir su obra hasta convertirla en paradigma inagotable.

Chris Marker - Christian Francois Bouche-Villeneuve- nació un veintinueve de julio de 1921 en Neuilly-Sur-Seine y murió en París un veintinueve de julio, noventa y un años después. La mayoría de documentos lo presentan como escritor, fotógrafo, cineasta-documentalista y artista multimedia: un orden que responde a la evolución de su obra polifacética pero también a la simultaneidad de medios técnicos y de expresión que terminó compaginando a lo largo de las más de cien películas que temáticamente abordan la problemática de la memoria, las muchas formas de revolución política del siglo XX, una reflexión permanente sobre el lenguaje audiovisual y la exploración de las nuevas tecnologías audiovisuales (Tranche, 2006: 280). Pero acaso la compaginación más profunda de Marker sea la de filosofía y poesía, es decir, su trasfondo de ensayista nato, en el más coherente de los sentidos. "Marker es considerado como el Montaigne del documental y él mismo considera que su función en el cine no es otra que la del ensayista. [...] Para Marker la fórmula ensayística tiene como soporte las imágenes documentadas reelaboradas a partir de la subjetividad camuflada y de los juegos con el texto literario" (Quintana, 2007: 133). Su filmografía, que dialoga constantemente consigo misma, integra ambas opciones ensayísticas, literaria y fílmica, como apoyo y consonancia la una de la otra.

Marker optó por reflexionar con y a través de imágenes documentales y de un cine catalogado "de guerrilla" — heredado de la tradición de los años treinta y de Joris Ivens-, combinado con "un tono personal irreprimiblemente montaignesco" (Lopate, 2007: 72). Además de seguir las tantas luchas anticolonialistas que en uno y otro enclave se gestaron en el siglo XX, toda su obra está dedicada "al propósito de develar los mecanismos de la memoria, las formas de dominación a través del control de esta y algunas claves para construir un proyecto personal y colectivo de memoria vital y sincera, o al menos sensata" (Álvarez, 2004: 42). Esta búsqueda hace que Marker aparezca también como un gran revolucionario de la enunciación y de la identidad del sujeto en el conocimiento mediante la interrogación de las imágenes. Así se expone en la antología hasta el momento más completa dedicada al cineasta 
en lengua castellana, donde se estudia Sans Soleil como vía "para explorar el vértigo del tiempo y la heraclitiana paradoja de la identidad del sujeto de conocimiento y la experiencia, del papel de las imágenes en todo ello y de la inútil tarea de confrontar las palabras y las imágenes en los términos tradicionales de comentario e ilustración" (Ortega y Weinrichter, 2006: 31).

El presente análisis tiene como objeto el estudio de Sans Soleil más allá del modo enunciativo del yo, campo hasta ahora más analizado por teóricos tan especializados como Català (2006), Weinrichter (2006) o el mismo Lopate (2007), entre otros. Si bien la implicación autoral queda expuesta en un punto introductorio por ser la base ensayística, este trabajo busca identificar, principalmente, los mecanismos y las técnicas audiovisuales con los que Marker traduce a lenguaje fílmico los principios de forma-pensamiento estipulados en la teoría literaria para la modalidad ensayística dentro del género argumentativo. Para ello se toma como base el esquema desarrollado por la investigadora y ensayista María Elena Arenas Cruz, Hacia una teoría general del ensayo. Construcción del texto ensayístico (1997: 451-458), el estudio más completo sobre teoría del ensayo publicado en lengua castellana. Autores como Bergala (2000), García Martínez (2006), Català (2014, 2017), Rascaroli (2017) y Cruz-Carvajal (2019) se basan en fuentes radicadas en el campo literario o filosófico, y aportan perspectivas para identificar formas de traslación del ensayo literario al fílmico. No obstante, se carece de observaciones rigurosas y estudios suficientes para abordar los mecanismos específicos de la escritura ensayística-audiovisual, incluso tratándose del modelo markeriano. Los apartados que siguen son, en consecuencia, el análisis de la puesta en práctica audiovisual de los fundamentos filosóficos de Adorno, Bense y Lukácks, sintetizados en seis ejes de observación: la manifestación de un yo reflexivo, el metalenguaje como revelación del proceso de hacerse la obra, la forma asistemática de la estructura, la heterogeneidad de los materiales, las figuras del pensamiento creadas en el lenguaje - fílmico-literario- y el diálogo con el receptor.

\section{Experiencias históricas en la imagen-memoria}

Como todo ensayo, Sans Soleil empieza por estar escrita "con motivo de". E1 autor rememora e interpreta diversas cuestiones de la Historia y la cultura — pasadas, presentes y futuras - sobre la selección de instantes vividos en varios viajes, especialmente a Japón y África, que quedan descritos fragmentariamente en cartas que un cámara trotamundos — Krasna, su álter ego — escribe a una amiga — voz en off de la actriz y escritora Florence Delay_- Marker/Krasna es un coleccionista de memorias: "Se puede decir que me he pasado la vida preguntándome sobre la función del recuerdo", cita Lopate (2007: 73) a Marker para concluir que asocia de forma explícita el recuerdo y la reescritura.

La primera propiedad ensayística sobre la que abundan análisis en torno a la obra markeriana es la forma enunciativa desdoblada, polifónica, caracterizada por fundir objetividad y emoción en proporciones iguales. "La base de la reflexión que plantea Marker a lo largo de su filmografía está construida, generalmente, a partir de múltiples voces enunciativas de origen marcadamente literario que, en vez de expresar un yo directo, proponen una especie de enmascaramiento de este yo" (Quintana 2007: 132). A esto debemos agregar que "también tiene el don aforístico del ensayista que le permite 
manifestar una personalidad histórica colectiva, un plural en primera persona incluso cuando la primera persona singular se mantiene en suspenso" (Lopate, 2007: 72).

La obertura $^{2}$ de Sans Soleil presenta de una vez y para el resto de la narración dos personas que irán inseparables: la primera y la tercera - $-\mathrm{y}$, dentro de esta, la primera persona del autor Krasna/Marker - . Aunque todos los comienzos de partes o de capítulos recaen en la lectora de las cartas — tercera persona: él escribió-, se vuelve frecuente que en el avance de los relatos las dos personas se fundan en un mismo bloque enunciativo, sin que medien pausas o giros narrativos. Simplemente se desdobla en un punto y seguido, como si se tratara del inserto de un plano en el montaje de una misma secuencia: "Me escribió que en las afueras de Tokio hay un templo consagrado a los gatos. Me gustaría saber decirte la simplicidad, la falta de afectación de esa pareja que vino a depositar al cementerio de los gatos una lata de madera cubierta de caracteres [...]"' (Álvarez et al., 1993: 6).

La reflexión verbal de Sans Soleil recae por principio en esta primera persona y sin duda es el contenido de mayor peso hacia el que terminan conduciéndose todas las anécdotas — como se verá en el punto sobre la estructura- Su implicación decisiva es la reflexión sobre las imágenes y el registro-proceso de la misma película que el espectador está viendo, en una función metafílmica insinuada desde la misma presentación y que emerge de modo recurrente en forma de alusión, junto con otros comentarios respecto al proceso, real o imaginario, de un trabajo fílmico: "Mi problema personal era algo más concreto: cómo filmar a las mujeres de Bissau" [...] "Seguramente nunca haré esta película" (Ibídem: 33).

El conjunto de estos ejemplos demuestra el cumplimiento riguroso del modo enunciativo de Sans Soleil respecto al macrogénero argumentativo y a los rasgos particulares del tipo ensayo. A modo de síntesis probatoria: monólogo subordinado al autor, con pruebas de la experiencia y afectivas para dar credibilidad. Sincretismo enunciador/observador/autor. Punto de vista del yo, no dogmático, en la percepción de una realidad compleja sobre la que su opinión es simplemente orientadora. Experiencia individual como objeto y método de conocimiento. Contenido emotivo y contenido conceptual sincronizados. Tono conversacional - en modo epistolar-. Ilusión de verdad autobiográfica. Tono asertivo en el uso del tiempo presente: aunque se refiere a viajes que ya fueron, el tiempo presente se utiliza especialmente para reflexionar sobre la memoria — ahora - y sobre el proceso fílmico.

\subsection{Yo he filmado y he montado}

Además del tono subjetivo y emotivo de la lectora de cartas — que en todo caso por sí misma no evidenciaría la presencia del autor, sino más bien un tono de intimidad-, la intervención del yo en Sans Soleil es relativa a las huellas que el director ha dejado en la materia visual y sonora, es decir, en sus manipulaciones y en sus manifestaciones y reflexiones metalingüísticas. Desde el primer momento, Marker se refiere a la imagen que el espectador está viendo y al largo plano en negro que la acompaña, evidenciando el estarse haciendo y desvelando el proceso de construcción del significado: si no vemos la felicidad de los niños, confía en que al menos veamos el espacio negro y, anterior a esto, que sepamos que se trata de una composición del montaje. A partir de

2 El/la lector/a de este artículo puede ver directamente el guion de Sans Soleil en este enlace (Álvarez, et al., 1993): https://n9.cl/el5ya 
ese momento, yo y metalenguaje son inseparables y surgen de modo recurrente entre los varios niveles de lenguaje y realidad que componen el film.

Con independencia de la intervención directa del comentario del yo, su impronta aparece en una manipulación de las imágenes y los sonidos que se efectúa de varias maneras, cumpliendo siempre funciones reflexivas y expresivas a veces muy polivalentes, y demostrando que "analizar una imagen exige no hacerla valer por sí misma sino cambiarla de contexto para mirarla mejor" (Weinrichter, 2006: 178). El efecto más sencillo es el congelado del fotograma, que en dos casos se corresponde con el énfasis de la interrogación o el comentario: “¿Cómo puede uno recordar la sed?", "[...] el umbral bajo el que cualquier hombre es tan bueno como cualquier otro, y lo sabe" (Álvarez et al., 1993: 9). Detener la imagen acentúa la pregunta o la sentencia, y es seguido de una prolongación silenciosa que también ejerce de pausa y transición, creando un espacio que permite al espectador continuar con la reflexión.

Algunas imágenes televisivas han sido ralentizadas o tratadas con desenfoques, movimientos de cámara sobre la pantalla, efecto barrido, reelaboración en edición y manipulación sonora. Uno de los ejemplos más bellos de desdoblamiento visual y recomposición del color está en relación precisamente con el comentario sobre la belleza encarnada en la actriz Natsume Masako (Imagen 1), "con un rostro y un nombre, como el horror de la guerra" (Ibídem: 19).

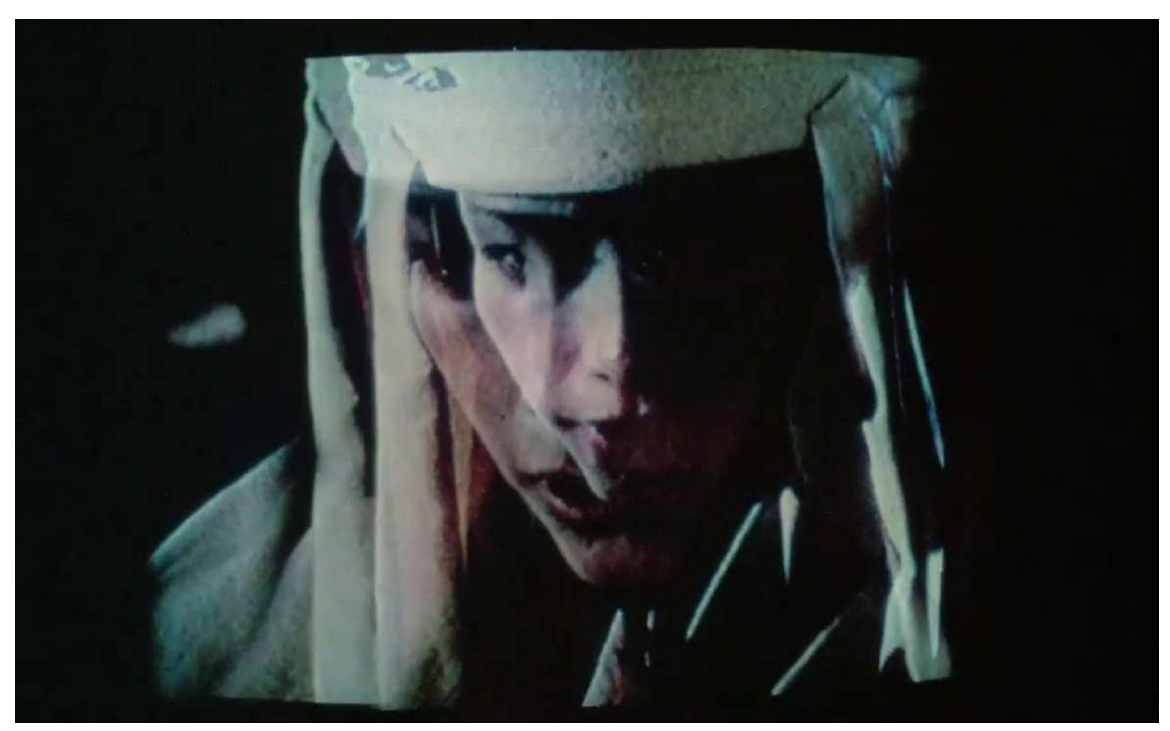

Imagen 1. Fotograma de Sans Soleil [Fuente: captura de pantalla]

Una muestra sobresaliente de exploración sobre las posibilidades plásticas de la textura electrónica, y al mismo tiempo de fusión estético-tecnológica al servicio del pensamiento crítico, es la solución visual que en una secuencia se nos ofrece para mostrar una clase de personas excluidas de la sociedad japonesa. Marker crea una correspondiente no-imagen, gracias a la manipulación electrónica del registro real de los excluidos. "Son no-personas. ¿Cómo pueden ser mostradas sino es como noimágenes?” (Ibídem: 52). 
En distintos sentidos y grados, las recomposiciones estéticas terminan provocando una reflexión y, de hecho, surgen condicionadas bajo un flujo de pensamientos. El yo de Marker queda así patentado con una poética donde la tecnología se ha explorado hasta dar de sí una poesía conceptual que en algún momento el autor apoya con la ayuda de Hayao Yamaneko, supuesto montador de Sans Soleil, quien "pretende que la memoria electrónica es la única que puede tratar el sentimiento, la memoria y la imaginación" (Ibídem).

Pero no todas las imágenes poéticas están sometidas a los efectos de edición de Yamaneko. Otras cuantas están conseguidas simplemente con efectos de iluminación, proyección y composición, o bien parecen haber sido descubiertas de repente, por ejemplo, a través de la lluvia mientras se acompañan del suave sonido de un sintetizador lejano, o tras la luz del invierno al fondo de una estación de tren.

\subsection{Metalenguaje y memoria}

La función metafílmica que de principio a fin se hace presente en Sans Soleil también produce alteraciones de la imagen hasta convertirlas en arte electrónico que combina borrado y recomposición — revisión de la memoria_-, observación de la tecnología del medio o recuperación y transformación de símbolos que, como la espiral de Vértigo — Vertigo, Alfred Hitchcock, 1958-, cumplen un papel de identificación/analogía respecto a la misma estructura interna de la película.

En los casos más representativos, el metalenguaje es producto de la interacción entre la voz/comentario y la imagen, es decir, en un acto de reflexión sobre esta, que guarda relación con el gran tema recurrente - tanto del autor en general como del film en particular - de la memoria en las imágenes. Como consecuencia, ese metalenguaje también puede implicar formas asociativas que siguen el flujo de la conciencia con exactitud suprema, como ocurre cuando el proceso del montaje que estamos viendo es resultado inmediato del seguimiento que hace el yo markeriano de su propia memoria, para crear una analogía que "monta" su contenido mental en este momento: "Mi memoria superpone dos torres, la del castillo en ruinas de Montpilloy, que sirvió de refugio a Juana de Arco, y la del faro en el extremo sur de la isla de Sal, uno de los últimos que funcionan con petróleo" (Ibídem: 72). La proximidad de los planos es sucesiva y su semejanza, de una gran precisión, descubriendo la extraordinaria memoria visual de Marker y su capacidad para reunir en el montaje un continuo espaciotemporal que realmente nos sitúa dentro de su flujo mental (imagen 2):
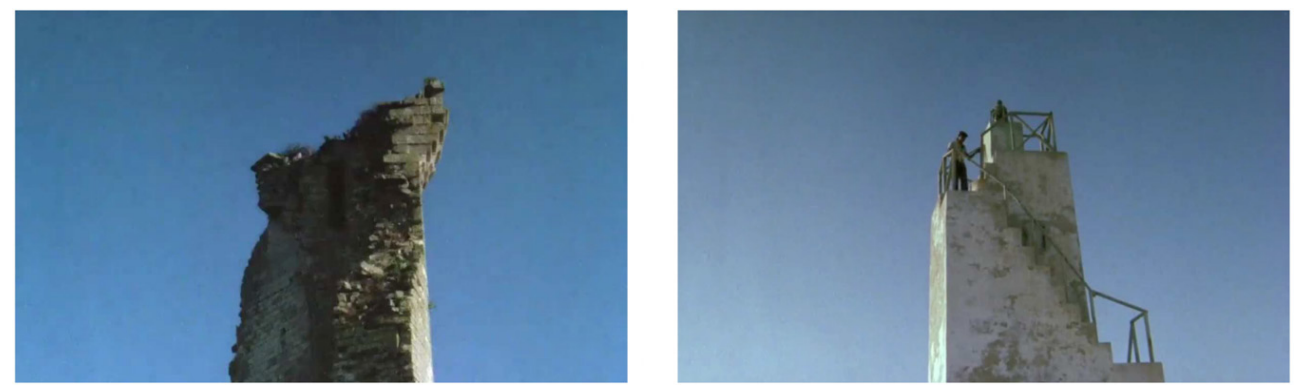

Imagen 2. Fotogramas de Sans Soleil [Fuente: captura de pantalla] 
Uno de los mecanismos metalingüísticos más importantes de Sans Soleil es el planteamiento de la existencia de una "Zona" virtual, alusión y homenaje a La Zona de Stalker (Сталкер, Andrei Tarkovski, 1979), una especie de mundo paralelo de imágenes y fenómenos potenciales que habita en el sintetizador de Yamaneko. Este recurso es empleado tanto para sintonizar las imágenes con ciertas dimensiones y relaciones de naturaleza espiritual — abordadas a través de las culturas que registracomo para poner bajo sospecha la verdad de las imágenes históricas, en especial, las televisivas.

Es así como el yo metalingüístico ha sido hilo conductor por encima o paralelo a los fragmentos de la narración, manifestándose como evidencia de rodaje y de montaje - estarse haciendo-, como flujo del pensamiento, como observación de la memoria, como reflexión, transformación y creación de las imágenes. Por tal razón, se entiende que Sans Soleil finalice retomando su proceso de ejecución, en un acto de coherencia con su propuesta introductoria.

\section{Macroestructura y fragmentación}

Más allá de su aparente devenir asistemático, la macroestructura de Sans Soleil puede dividirse siguiendo dos criterios: el primero es el que se estipula para el ensayo literario dentro del macrogénero argumentativo (Arenas, 1997: 451-458); el segundo es el que establece el ritmo de la exposición, con su concentración de registros, anécdotas y reflexiones, separadas por las transiciones sonoro-visuales y los giros más importantes en la lectura de las cartas. El primero indica más un orden expositivoargumental, y el segundo, más un flujo reflexivo. Ambos coinciden al principio y al final, es decir, en la parte introductoria/presentación y en el cierre/recapitulación.

El exordio - Obertura, en el guion - presenta el modo enunciativo sobre una imagen - la de tres niños en Islandia - que estará editada como el espectador la está viendo - metalenguaje - pero con una reflexión sobre su posible significado: la felicidad o la conciencia de la misma película.

Narración-Exposición -Actos 1, 2 y 3 en el guion-. Fragmentos de cartas originados en viajes de Krasna/Marker. Trozos de memoria seleccionados e interpretados tanto por el autor original como por la lectora de cartas - que también es el autor- De la narración se desprende la argumentación / reflexión. El Acto 1 presenta las directrices temáticas, geográficas, históricas, reflexivas y metalingüísticas de las que parte la argumentación y en las que se centrará por pequeños capítulos más adelante o bien retomará con distintos métodos vinculantes entre fragmentos, muchos de ellos resueltos con figuras estilísticas como digresiones, analogías, comparaciones y asociaciones con las que se configura una red estructural profunda en forma de espiral.

Argumentación — reflexión-: deriva de la narración de fragmentos y está dentro de ella a modo de memoria capturada en imágenes actualizadas con la perspectiva del tiempo en esta narración/carta que el espectador está viendo. Se basa en las vivencias personales como prueba, pero en algún momento contextualizadas en marcos históricos y culturales objetivos - viajes concretos a lugares concretos, anécdotas concretas, fechas concretas, acontecimientos concretos, guerras concretas, personajes históricos concretos-, para dar lugar a una reflexión sobre la Historia en la memoria, entre otras meditaciones más universales y abstractas. 
El principio argumentativo hace que el flujo reflexivo no se produzca de cualquier manera: hay un ritmo expositivo que incluye "cierres" o giros con el apoyo de muchas pequeñas conclusiones que parecen surgir de modo espontáneo en medio del conglomerado de comentarios y de anécdotas. Otras veces - las más contundentes- se producen como resultado inevitable del cúmulo de fragmentos y de relaciones que les antecede.

Epílogo - contenido en el Acto 4 del guion-: corresponde a los últimos quince minutos de la película y se produce a partir de una digresión en al Acto 4. El epílogo de Sans Soleil cumple rigurosamente con la función de retomar los elementos protagónicos del comienzo - por tercera vez, los tres niños de Islandia y el consiguiente metalenguaje-, asociar de nuevo y por último las líneas capitales de reflexión - Historia, memoria, película - tanto en el texto como en la imagen. Al conectar con el exordio y con las reflexiones centrales de los puntos anteriores, se llega "al final del camino de la memoria", frase de una última carta (Ibídem: 79).

De esta manera queda cerrada la macroestructura en su condición de trayectoria argumentativa. Pero a continuación el autor retoma el nivel anecdótico del fragmento para dejar el espacio abierto al receptor con la gran pregunta que nos comparte su intermediaria destinataria: “Habrá algún día una última carta?” (Ibídem: 91).

\subsection{Una espiral de constelaciones}

La estructura arborescente de Sans Soleil podría responder a tres grandes niveles o capas, simultáneas e intervinculadas:

Referentes geográficos: Japón y África; Islandia, San Francisco y Hong Kong;

Relaciones y reflexiones culturales e históricas: entre y dentro de los dos primeros (Japón y África);

Metalenguaje: espacio virtual donde están tratados los registros de la memoria y donde todos los referentes terminan interconectados por efecto del flujo de la reflexión.

Como en todo ensayo, la macroestructura de Sans Soleil está compuesta por constelaciones (Adorno, 1962: 24), que aquí son fragmentos de cartas. Se trata en primer lugar de una selección que ha hecho la memoria y el proceso reflexivo de Krasna, filtrados a su vez por la selección que hace la lectora de cartas para el espectador. No sólo ninguna carta se lee completa - ninguna es un relato con principio-nudo-desenlace, ni entre todas lo conformarían-, sino que además no se presentan con ningún criterio de orden, ni cronológico ni geográfico. A eso se añade que cada fragmento, por más pequeño que sea, salta de un plano a otro - tanto de la realidad como del pensamiento- en permanente fluidez.

Dentro de esa estructura herética y extraordinariamente híbrida, de todas maneras, también se cumplen sistemáticamente dos leyes: la amplificación —universalización o eternización - del fragmento o gesto y el principio fractal de la forma espiral, desde la macroestructurura hasta cada uno de los fragmentos, es decir la eternidad y lo grande en lo pequeño y en el instante. Valga el desglose (Imagen 3) visualizado en pequeños bloques de esta constelación que hemos seleccionado para entender mejor la fractalidad de las microestructuras interconectadas en forma de espirales dentro de otras: 


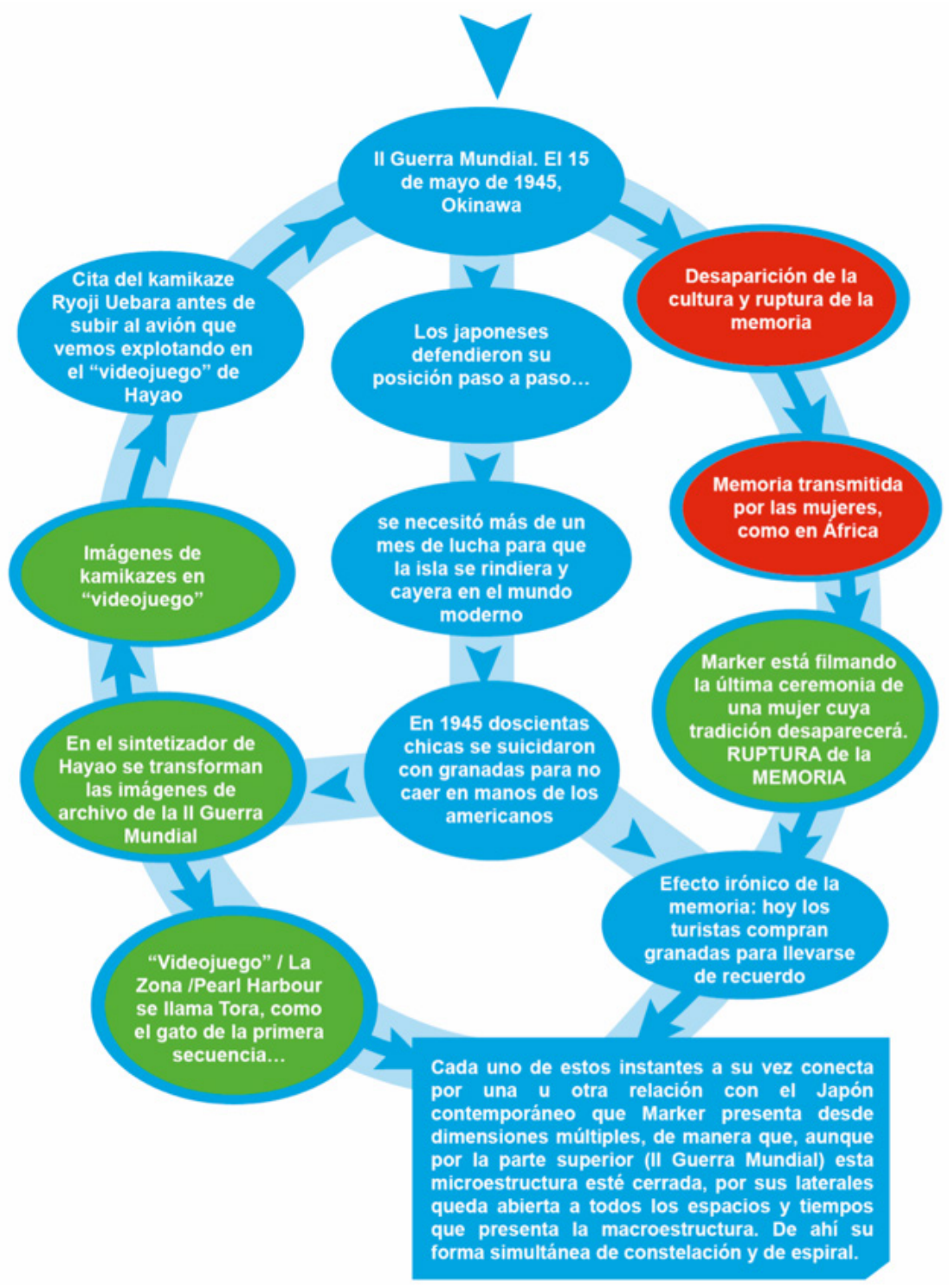

Imagen 3. Microestrutura o constelación de un fragmento de Sans Soleil.

[Fuente: elaboración propia]

El fragmento empieza rememorando la invasión perpetrada por Estados Unidos contra Okinawa el quince de mayo de 1945 y termina con la lectura del testimonio de un kamikaze minutos antes de subirse a un avión que vemos explotar tras los efectos electrónicos del sintetizador de Yamaneko. En este recorrido, una carta de Krasna también ha ido contando lo que pensaba cuando estaba filmando la última ceremonia de una tradición que pronto se perderá.

Esta microestructura — que ya viene conectada a un tronco histórico-geográfico llamado Japón y a otros temas transversales como el horror, las heridas y la guerrava circulando sucesiva y simultáneamente de la Historia al presente de una tradición 
y de esta a la pérdida de memoria y de esta a la imagen que de la II Guerra Mundial tienen hoy los turistas y a la vez al metalenguaje del sintetizador que procesa las imágenes de la II Guerra Mundial mientras se rememoran las últimas palabras de un kamikaze. Esto señala una organización de relaciones que se mueven de forma secuencial y transversal al mismo tiempo, una estructuración que pareciera incluso sobrepasar la fragmentariedad asistemática del ensayo normativo, al no regresar nunca al mismo hilo, sino encontrar en el interior de cada fragmento una conexión con los otros, que los reconecta desde dentro, sin necesidad de retomar una trayectoria conductora. Semejante capacidad de cohesión holística es posible gracias a las figuras estilísticas que se estudian más adelante.

\subsection{El flujo sonoro}

Además del metalenguaje, el flujo de la conciencia markeriana se manifiesta en Sans Soleil con el empleo de recursos sonoros permanentes para dar una continuidad expresiva al conglomerado discontinuo de fragmentos recordados-pensados. En varios momentos el sentido de la sonorización se basa en un compuesto de reverberaciones que conforman capas sobre capas, en equivalencia con el tratamiento de las imágenes sometidas a transformaciones electrónicas y también en correspondencia con las capas de la estructura temático-reflexiva.

Los recursos sonoros para estos efectos son muy sutiles y también muy sencillos: a tono con la procedencia y la calidad técnica de las imágenes — véase más adelante los recursos disímiles - Identificarlos exige del receptor una gran capacidad y voluntad de escucha, al punto de que casi podría pensarse que Marker no quiere que los descubramos. Sin embargo, que una gran cantidad de sonidos-flujo pasen inadvertidos nada tiene que ver con la percepción y los efectos de una distancia latente de continuidad reflexiva sobre lo que se muestra: "Se trata de encontrar una contemplación pura de las imágenes, ajena a la cultura del espectáculo y a la interpretación simbólica" (De Lucas: 1).

Con independencia de la voz en off, casi todos los sonidos parecen extraídos de algún campo de la experiencia real: ruidos de la naturaleza, programas de televisión, noticias de la radio, contenido sonoro de imágenes de archivo, videojuegos, fondo sonoro humano y música-ruido. Son reutilizados muchas veces en un tono especialmente bajo acompañando imágenes que no coinciden con su fuente. Otros sonidos son reverberaciones que en algunas - muy contadas - ocasiones se presentan como una "musicalización" muy lejana. Otros sonidos pueden ser una mezcla de varios de los anteriores. Y para unos últimos resulta muy difícil o imposible descubrir alguna procedencia o identidad.

En ningún caso, sin embargo y por las características descritas, podemos referirnos a una banda sonora que esté por encima - over- de las imágenes. Hay una distancia y con mucha frecuencia una falta de correspondencia entre estas y los sonidos, antes que un sometimiento del sonido respecto a la referencialidad o a la emotividad de los contenidos visuales. Se trata, una vez más, de la evocación de la conciencia.

\subsection{Retazos que piensan}

Los recursos que en este film utiliza Marker para componer sus fragmentos, y especialmente para dar unidad o cuerpo a la reflexión, se pueden agrupar en li- 
terarios y fílmicos. Dentro de los primeros, la heterogeneidad viene implícita en los mismos referentes que el contenido mental cohesiona. El segundo recurso es el de las citas, menos frecuente pero empleado para dialogar con las imágenes, enfatizar sentencias u ofrecer testimonios directos de la Historia e imprimir así mayor credibilidad/objetividad a los relatos o los registros visuales: "Basho había escrito: El sauce contempla al revés la imagen de la garza" (Álvarez, et al., 1993: 18). En el grupo de los recursos audiovisuales se encuentran los sonidos capturados de la realidad, comentados anteriormente: fragmentos de ruidos reutilizados y combinados con imágenes a las que descontextualizan. Por otra parte, están los retazos fílmicos y televisivos que se alternan con el cúmulo de imágenes capturadas en los viajes con su cámara de dieciséis milímetros. Igual que ocurre con el reciclaje sonoro, una gran parte de las imágenes de las que Marker se apropia para reutilizar al servicio de su flujo mental están retocadas o recompuestas, concretamente las extraídas de la televisión, "enmarcadas" algunas en una pantalla de televisor (Imagen 4).

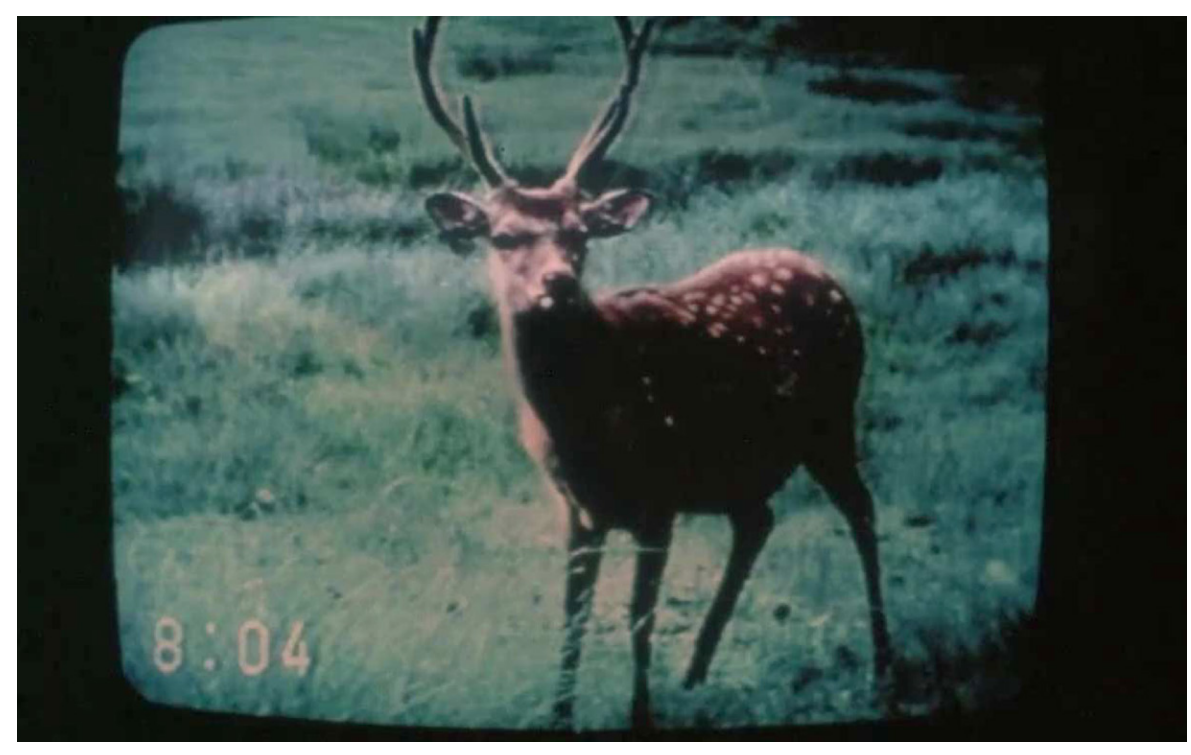

Imagen 4. Fotograma de Sans Soleil [Fuente: captura de pantalla]

Algunos recursos de apropiación actúan como auténticos documentos históricos inalterados, mientras que otros ejercen el papel de comentario o de cita demostrativa, o bien pueden estar a medio camino entre la memoria y el símbolo particular que alude a la estructura en forma de espiral. Muestra de ello son las fotos de Vértigo: la mayoría se insertan alternas al presente de las imágenes que Krasna ha capturado en un viaje a San Francisco, cuyo objetivo ha sido reconstruir algunos episodios y lugares de dicho film. El resultado son analogías visuales que vinculan distintos tiempos: el de la ficción, el de la memoria y el de la propia construcción de Sans Soleil. Este es un ejemplo entre muchos de cómo en el más puntual de los recursos se pueden encontrar múltiples funciones y combinaciones. 


\section{El estlilo es el montaje}

Siguiendo las mismas propiedades de los puntos anteriores, el que concierne a la voluntad de estilo mediante las figuras del lenguaje también se debe analizar partiendo del guion literario y, posteriormente, de la construcción audiovisual, lo que no descarta que parte de los mecanismos más efectivos de la reflexión expresiva se produzca precisamente en la relación palabra-imagen.

Puesto que el pensamiento y el flujo de la conciencia necesitan apelar constantemente a la expresividad, el lenguaje figurado está implicado en todos los principios que particularizan el texto ensayístico de Sans Soleil. Eso explica que en los puntos inmediatamente anteriores hayamos abordado tangencialmente muchas estrategias que en este apartado identificamos con ciertas denominaciones retóricas, de las que se seleccionan algunos ejemplos (dejando por fuera ejemplo de metáforas, interrogaciones, ironías, comparaciones y paradojas):

Digresión: "La poesía japonesa no califica. Hay una manera de decir barco, roca, rocío, rana, cuervo, granizo, garza, crisantemo, que lo contiene todo. La prensa habla estos días de la historia de ese hombre de Nagoya [...]" (Ibídem: 13).

Hipotiposis: "Todo un mundo de vagabundos, de lumpen, de desclasados, de coreanos. Demasiado destruidos por la droga, se emborrachan con cerveza, con leche fermentada" (Ibídem: 8).

Hipérbole: "Cómo no reconocer esta imaginería que va del barroco plastificado al estalinismo obsceno, esos rostros gigantes que pesan sobre la mirada, pues los voyeurs de imágenes son vistos a su vez por imágenes más grandes que ellos" (Ibídem: 15). Estas frases se acompañan de planos que registran la hipérbole real: un cartel que ocupa una calle por donde pasan transeúntes que, en comparación, son diminutos.

Muchas relaciones comparativas son extraídas de la observación de la realidad y pasan a convertirse en contenidos literarios o en relatos audiovisuales. Ejemplo de ello es el dondo-yaki - ceremonia japonesa donde se queman cosas para inmortalizarlas - que también puede hacer la naturaleza de vez en cuando, como lo hizo con la erupción volcánica de la ciudad de Heimaey en 1973 - y cuyas casas enterradas en la ceniza se muestran en imágenes- - Un segundo gran ejemplo viene acompañado del humor con el que Marker descubre y registra la metáfora de algunos juegos mecánicos respecto a las jerarquías socio-laborales en Japón —que podrían trasladarse perfectamente al sistema occidental—. Y la tecnología, a su vez, será la creadora de otro tipo de relaciones y efectos significantes e incluso terminará convertida en el lugar de lo potencial en el interior del sintetizador de Hayao Yamaneko: "La Zona" es la moviola donde se está creando/editando Sans Soleil, intercomunicando todas las dimensiones de la experiencia y de la conciencia markeriana.

\subsection{Figuras laterales}

Los mecanismos más importantes de interconexión entre capas narrativas se producen con el montaje entre sonidos e imágenes y entre imágenes — dentro de los fragmentos/secuencias y en sus transiciones o cambios-. Lo primero es relativo a los significados o estados que surgen del montaje lateral, del que ya hemos comentado algunos efectos del flujo sonoro que alteran la percepción habitual de las imágenes, distanciándolas para favorecer la reflexión sobre ellas. 
Un ejemplo de separación significativa sonido-imagen, que equivaldría a un oxímoron y a una paradoja, es el que se presenta cuando en un fragmento el texto cuenta la historia de Sei Shônagon a comienzos del siglo XI y reflexiona sobre el origen del gusto japonés por las cosas pequeñas. Mientras la voz en off se refiere a la pasión que Shônagon sentía por las listas de "cosas elegantes", "cosas angustiosas" e incluso "cosas que no merece la pena hacer" (Ibídem: 27), las imágenes muestran misiles y bombarderos. Las palabras se refieren al pasado y la imagen nos habla del presente, poniéndonos ante una paradoja donde uno de los significados podría ser el abismo de la Historia: algo que conectará con el tópico de la memoria y de la pérdida de las tradiciones y de la identidad como consecuencias de la transculturación japonesa posterior a la II Guerra Mundial.

La epifanía surge como efecto contundente de la correspondencia eventual entre texto e imagen (Català, 2006: 161). En estos casos, ambos coinciden en el mismo referente, pero justamente para reflexionar sobre esas imágenes con la distancia del tiempo. El objetivo es similar a la reflexión ilustrada con las listas de Shônagon mientras vemos misiles y bombarderos: situarnos en dos tiempos para examinar la relación entre el pasado y el presente, muchas veces con las imágenes de la Historia como intermediarias. Lopate (2007: 72) lo explica como la proyección de "una comprensión histórica sobre un material que de lo contrario sería trivial o neutral" y destaca el momento de la entrega de medallas en Cabo Verde — las que en 1980 han registrado el acto - , cuando el texto —en 1981 - explica que hace falta avanzar un año en el tiempo para que podamos saber que ese hombre al que el presidente está entregando la medalla será quien le derrocará.

Al igual que una buena cantidad de episodios, este se cierra con la imposición del silencio - ausencia de texto- sobre la imagen, un espacio grande y definitivo que Marker, deliberada y generosamente, deja abierto al espectador para que pueda hacer sus propias meditaciones. Al mismo tiempo, esos silencios sirven de pauta para marcar el ritmo de la estructura, demostrando una vez más que la asistematicidad de Sans Soleil, como la de todo ensayo riguroso, tiene determinada su propia organización.

\subsection{Figuras proposicionales}

Si bien el montaje lateral forma parte de ese flujo sonoro continuo donde se instala la reflexión, las figuras cognitivo-expresivas más evidentes son las que se producen en el montaje proposicional, con dos criterios: uno, entre las imágenes discontinuas de un fragmento que inserta planos de otro en una alternancia significante; dos, en el paso de uno a otro fragmento con la continuidad que le permiten ciertas analogías visuales y conceptuales.

Un ejemplo de las figuras expresivas que interconectan significativamente el interior de los fragmentos - $\mathrm{y}$ a estos con el interior de otros fragmentos entre sí- - lo encontramos en la comparación que se hace entre Hayao Yamaneko con un videojugador, utilizando una serie de insertos que combinan planos de un videojugador cualquiera, perteneciente a otra parte del film, con imágenes producidas por el sintetizador donde Yamaneko está editando Sans Soleil (Imagen 5). 

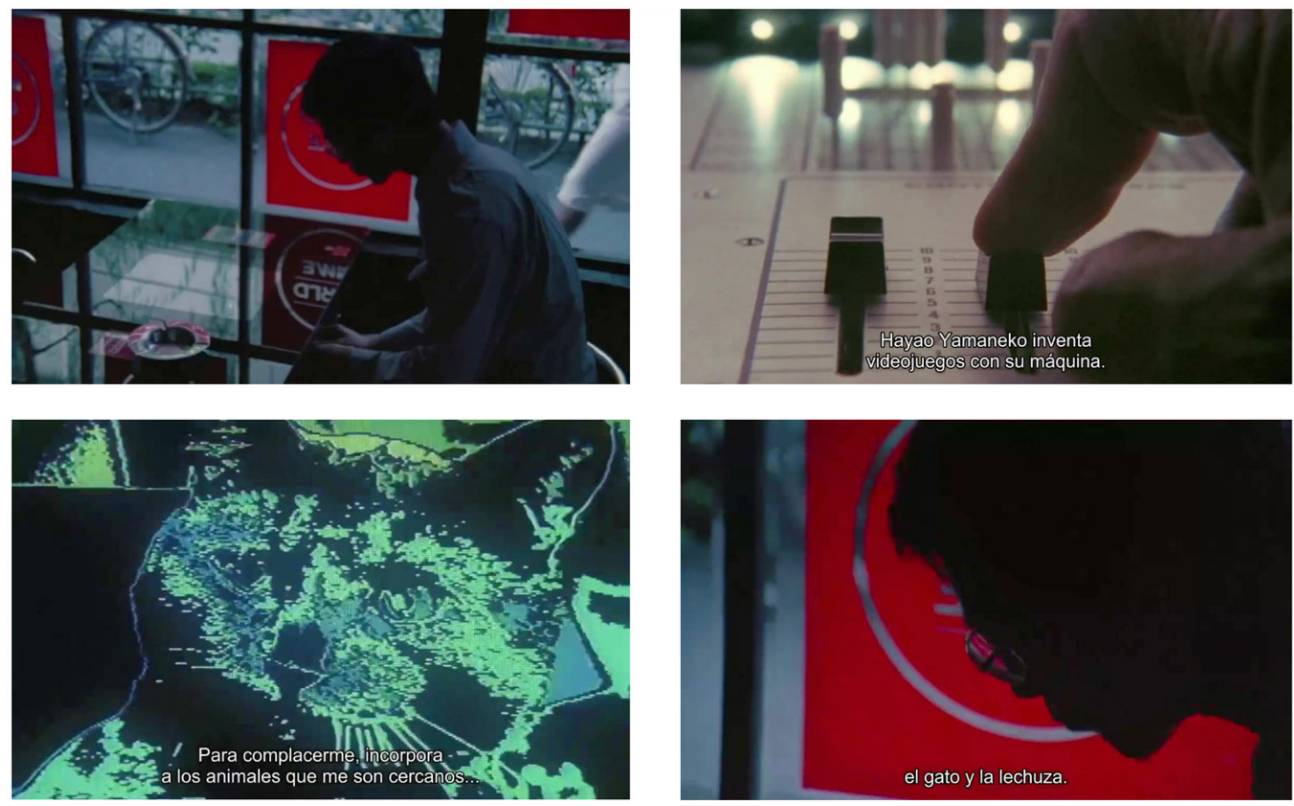

Imagen 5. Serie de fotogramas de Sans Soleil [Fuente: captura de pantalla]

Los contrastes rítmicos y de otros tipos también son utilizados en el paso de unos fragmentos a otros y pueden ir acompañados con otras relaciones estilísticas como las analogías visuales o temáticas. Tales transiciones también pueden revelar oposiciones, como aquella que expresa las grandes diferencias ideológico-generacionales significadas en el paso de los planos de la juventud militante de los años sesenta a los de la adolescencia "marciana" de los ochenta.

El montaje proposicional es casi siempre, entonces, el equivalente a una digresión que crea significados o que es un significado en sí mismo, y es la forma que naturalmente adopta la estructura asistemática de Sans Soleil, puesto que su escritura se basa en una simultaneidad de relaciones antes que en una secuencialidad narrativa o expositiva. No obstante, la expresividad de Marker pasa, como se puede comprobar en algunos ejemplos anteriores, por un afán estético que busca analogías materiales para dar una continuidad conceptual a través de la relación visual. En los casos de mayor valor poético tales asociaciones obedecen, justamente, a la trayectoria fluida de una memoria que zigzaguea armónicamente en distintos tiempos y espacios.

\section{El observador mirado}

La primera estrategia de diálogo entre Marker y el espectador es la propia del género epistolar con la que establece una enunciación que parece interpelarnos a través del corresponsal ausente - su álter ego Krasna- . Puesto que el autor no cree en la comunicación de nuestra época agonizante (Rascaroli, 2009: 34), su intercambio real con nosotros depende de la dirección en que la persona que nos habla se sitúa respecto a lo que muestra, es decir, la distancia que permanentemente establece Sans Soleil para la reflexión y que depende de todos sus mecanismos 
cognitivo-emotivos desarrollados en sus distintos niveles de lenguaje: desde el guion que interpela con sus tantas preguntas en segunda persona, desde la estructura ametódica y abierta que el espectador al final tiene que cerrar por sí mismo, y desde la complicidad que se produce al seguir el flujo del pensamiento markeriano. Pero también hay un diálogo constante entre el lenguaje fílmico y el espectador. Además de todas las figuras estilísticas expuestas en el numeral anterior, generadas en las relaciones sonido/imagen e imágenes entre sí, la intención dialógica de Marker se traduce en varios tipos de miradas hacia la cámara a través de las que nos interpela hasta el final (Imagen 6).
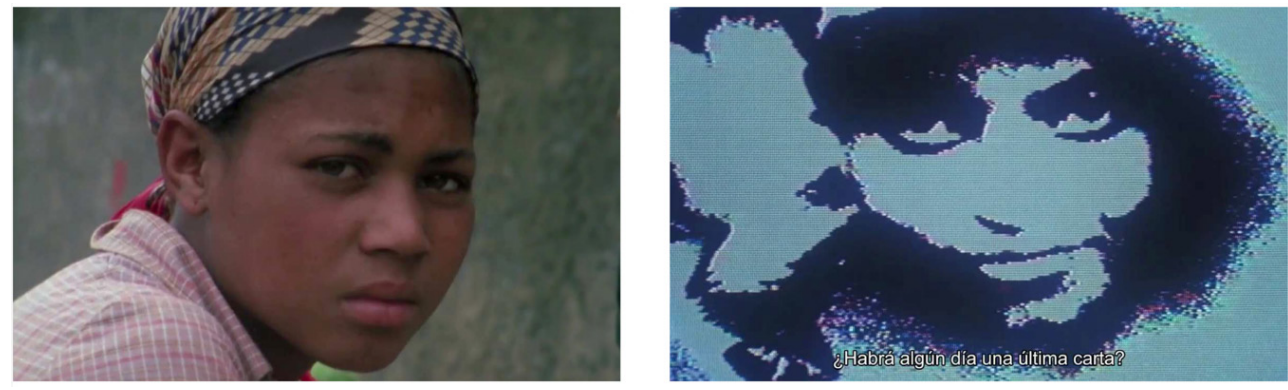

Imagen 6. Fotogramas de Sans Soleil [Fuente: captura de pantalla]

La mirada de las imágenes al observador forma parte de la extensa cantidad de recursos metafílmicos que usa el autor para implicarnos en su poética inagotable, más allá de los que atañen al texto literario, a la apertura de la estructuración y a la expresividad de sus figuras estilísticas. Y en la medida en que la presencia de Marker se revela a través de la propia observación de sí mismo y de su lenguaje, más nos exige que interaccionemos de vuelta, para continuar de llenar — con nuestra razón y nuestra emoción, por partes iguales - sus significados interminables.

\section{Conclusiones}

La aproximación analítica de las páginas anteriores confirma la correspondencia canónica de Sans Soleil con los principios ensayísticos del macrogénero argumentativo, partiendo de sus funciones enunciativas. La hermenéutica, al ser un compuesto de interpretaciones respecto a la cultura, la sociedad y la Historia de todos sus referentes. La testimonial, a través de cartas que son el principio de las constancias de la relación afectiva con lo que Marker expresa sus sentimientos y pensamientos. La metadiscursiva, presente en especial a partir de la reflexión de las imágenes y su montaje, revelando su proceso de estarse haciendo y pensándose a sí misma. La de comunicación, mediante los mecanismos dialógicos del estilo epistolar. Y la ideológica, al transmitir todo un sistema de valores respecto a la Historia, la sociedad y los seres humanos a lo largo y ancho de sus expresiones y pensamientos, al punto de confiar que en el año 4001 el cerebro alcanzará su grado máximo de empleo y cada ser humano "compondrá su propia lista de cosas que hacen latir el corazón, para regalarlas o para borrarlas", en un mundo donde además cada memoria creará su propia leyenda y la poesía será hecha por todos. 
En Sans Soleil la reflexión y la conciencia son la forma del montaje - que por supuesto incluye el sonido-, tanto si hablamos de la macroestructura como si nos referimos a cada fragmento/constelación en particular. De todos los ejemplos comentados se concluye que las figuras estilísticas de Sans Soleil son el gran secreto de interconexión espaciotemporal e interdimensional de su estructuración asistemática. Obedecen a la forma de la conciencia-memoria del autor por encima de la acumulación de los múltiples fragmentos de su experiencia. Al ser resultado de sus procesos reflexivos, dependen del montaje y no se pueden separar del metalenguaje ni de la presencia del yo. Como en el ensayo literario, la efectividad que todo esto les confiere las lleva a cumplir la triple función estético-emotiva, cognoscitiva y argumentativo-persuasiva que a su vez está implicada en el principio de diálogo con el receptor.

A través de todos sus mecanismos de ensayo, el flujo de la conciencia markeriana hace que el espectador se implique y dialogue con dos mundos: el histórico de su experiencia política — en el más amplio de los sentidos — y el potencial/virtual de su creación poética, donde todas las cosas se comunican, como en una representación de la Noosfera: ${ }^{3}$ esa red invisible de interconexiones espaciotemporales en medio de las que tal vez Sans Soleil también forme parte de un sueño colectivo en un mundo paralelo fuera del tiempo.

\section{Bibliografía}

Adorno, Th. (1962). "El Ensayo como forma”. En Notas de Literatura (pp. 13-35), Barcelona: Ariel.

Álvarez, M. (2004). "Chris Marker en el festival de cine independiente de Barcelona. El cine de las imágenes que tiemblan". En Kinetoscopio, 68, 40-48.

Álvarez, M.; Redín, A.; Costa, S. (trad.), [año original: 1993]. Sin Sol [traducción del guion original publicado en Trafic, $\mathrm{n}^{\circ} 16$. Recuperado de: https://n9.cl/el5ya

Arenas Cruz, M. E. (1997). Hacia una teoría general del ensayo. Construcción del texto ensayístico. Cuenca: Ediciones de la Universidad de Castilla-La Mancha.

Aullón de Haro, P. (1992). Teoría del ensayo. Madrid: Verbum.

Bense, M. (1942). Über den Essay und seine Prosa. En Merkur, I, 414-424. Recuperado de: https://n9.cl/wysvz

Bergala, A. (2000). “Qu'est-ce qu'un film-essai?". En Astruc (ed.), Le film-essai, identification d'un genre. París: Bibliothèque Centre Pompidou.

Català, J. M. (2006). "La forma ensayo en Marker". En Ortega; Weinrichter (eds.), Mystère Marker. Pasajes en la obra de Chris Marker (pp. 149-164). Madrid: T\&B Editores.

Català, J. M. (2014). Estética del ensayo: la forma ensayo, de Montaigne a Godard. Valencia: Universitat de València.

Català, J. M. (2017). Viaje al centro de las imágenes: una introducción al pensamiento esférico. Santander: Shangrila.

Corrigan, T. (2011). The essay film: from Montaigne, after Marker. New York: Oxford University Press.

En torno a este concepto, Coureau (2004: 224) tiene un análisis sobre distintos fragmentos de Godard y Marker, con los que demuestra que sus investigaciones relativas a la escritura fotográfica y del montaje con los nuevos medios se orienta hacia la representación de una cuarta dimensión que Sans Soleil traduce con la evocación de La Zona tarkovskiana que aquí mencionamos en el punto 2.2 . 
Coureau, D. (2004). "Poétique filmique de la Noosphère (Jean-Luc Godard, Chris Marker 1982-2001)". En Liandrat-Guigues; Gagnebin (eds.), L'Essai et Le cinema (pp. 217-225). Seyssel: Champ Vallon.

Cruz-Carvajal, I. (2019). "Hacia una gramática del ensayo audiovisual”. En Sierra y Alberich (eds.), Epistemología de la comunicación y cultura digital: retos emergentes (pp. 285295). Granada: Editorial Universidad de Granada.

Cuesta, M. (2009). "Notas sobre el ensayo". En Nómadas. Revista Crítica de Ciencias Sociales y Jurídicas, $\mathrm{n}^{\mathrm{o}} 21$ (2009.1). Madrid: Universidad Complutense.

De Lucas, G. (1999). Chris Marker. Composición politica de la imagen. Introducción a la primera imagen de Sans Soleil. En: https://n9.cl/wo9b

Deltell, L. (2019). "Oficio en las tinieblas: el ensayo audiovisual en un país en crisis". En Mínguez (ed.), Itinerarios y formas del ensayo audiovisual. Madrid: Gedisa.

García Martínez, A. N. (2006). "La imagen que piensa. Hacia una definición del ensayo audiovisual". En Comunicación y Sociedad (pp. 75-106). Revista de la Facultad de Comunicación, Vol. 19, nº. 2. Pamplona: Universidad de Navarra.

Gómez-Martínez, J. L. (1981). Teoría del ensayo. Salamanca: Ediciones Universidad de Salamanca.

Lopate, Ph. (2007). A la búsqueda del centauro: el cine-ensayo. En Weinrichter (ed.), La forma que piensa. Tentativas en torno al cine-ensayo (pp. 66-89). Pamplona: Fondo de publicaciones del Gobierno de Navarra.

Lukács, G. (1975). Sobre la esencia y forma del ensayo (Carta a Leo Popper). En El alma y las formas. Obras Completas I (pp. 16-39). Barcelona: Grijalbo.

Machado, A. (2007). "El film-ensayo". En La Ferla, Jorge (comp.), El medio es el diseño audiovisual. Manizales: Ediciones Universidad De Caldas. En https://n9.cl/6rw5m

Mínguez, N. (ed.) (2019). Itinerarios y formas del ensayo audiovisual. Madrid: Gedisa.

Ortega, M. L.; Weinrichter, A. (eds.) (2006). Mystère Marker. Pasajes en la obra de Chris Marker. Madrid: T\&B Editores.

Quintana, Á. (2007). “Al principio fue el verbo. Notas sobre el ciné-essai”. En Weinrichter (ed.), La forma que piensa. Tentativas en torno al cine-ensayo (pp. 26-140). Pamplona: Fondo de publicaciones del Gobierno de Navarra.

Rascaroli, L. (2009). The Personal Camera. Subjective Cinema and The Essay Film. London: Wallflower Press.

Rascaroli, L. (2017). How the Essay Film Thinks. New York: Oxford University Press.

Tranche, R. (2006). De la foto al fotograma. Fotografia y cine documental: dos miradas sobre la realidad. Madrid: Textos Documenta - Ocho y Medio.

Weinrichter, A. (2006). “Montaigne Marker”. En Ortega; Weinrichter (eds.), Mystère Marker. Pasajes en la obra de Chris Marker (pp. 171-184). Madrid: T\&B Editores.

\section{Películas citadas}

Stalker (Сталкер, Andrei Tarkovski, 1979)

Vértigo (Vertigo, Alfred Hitchcock, 1958) 